\title{
The Study of the Application of New Energy in the Development of New Product
}

\author{
$\mathrm{HeFei}{ }^{1, a^{*}}$ \\ ${ }^{1}$ School of Design Art, Ceramic Institutes of Jingdezhen,China \\ aemail:h_fei1225@126.com
}

\begin{abstract}
Keywords: New energy; New product development; Resources; Environment
Abstract. Now human beings are facing three major issues: resources, environment and population. Environmental problems are closely related to resources and issues of resources are the main reason of environmental problems. With the deterioration of environmental problem, people attach more importance to the study of environmental protection and other issues pertinent to it. New energy with little pollution and large reserves is of great importance to cope with environmental contamination and resource depletion. The paper will discuss the combination of new energy and new product in the light of the application of new energy, and sum up its characteristics.
\end{abstract}

\section{Summary}

In the late 60 s of 20 th century, the American design theorist Victor-Papanek proposed that "Design should take into account the use of limited resources on the earth and serve the protection of global environment." In the process of the development of new product, both enterprises and product designers should consider the issues of resources and environment. Under the background of low-carbon economy, how to reduce energy consumption and carbon dioxide emissions of the new product comparing to the old ones and to reach the goal of low energy, low consumption and low expense are big questions to each enterprise and designer. The use of new energy has mitigated the current situations of resource depletion and serious environmental pollution. At the current stage, the study and development of new energy has been one of pivot areas in industrial and technical competitions globally.

\section{Features of the application of new energy}

Nowadays global competition is fierce, so the worldwide all deploy the strategy of product first, the development of new product becoming the crux of enterprises and also the core strategy of their survival and development. Against the backdrop of low carbon, the development of new product should base on the following aspects: it should be compliant with energy-saving, efficient and environmental economic policy; the enterprise needs to develop new product in constant way to reduce energy consumption and environmental contamination under the pressure of uprising competition; the wakening of consumers' conscious of environmental protection urges the enterprise to develop low-carbon new product; the development of science and technology provides cleaner and more efficient new energy for new product; the modifications of existing product should not only lie in form, function, structure, material and so on, but also its dependent energy like choosing cleaner and more efficient energy. The discussion of the combination of new energy and new product will play a key role in constructing a low-carbon and environmentally friendly society. In a general view of new products in recent years, it is not hard to find that many products have been improved by using new energy. What's more, though new energy cannot be widely used in a short period, it is still the trend for building a low-carbon society. It has fulfilled the needs of consumers and needs to construct a low-carbon society, under which condition, the application of new energy to the development of new product bears the following features. 
New energy is generally applied to the products with heavy pollution and excess carbon dioxide emissions. The goal of using new energy is to save energy and protect environment. By using new energy in new product, pollution can be reduced and the damage to environment will lighten.

Vehicle, highly dependent on oil, its exhaust is especially of severe damage to environment. Comparing to vehicle with gasoline and diesel as power, at present the new energy vehicle uses unconventional vehicle fuels as power with its function and appearance unchanged. The development of new energy vehicle renders people getting rid of the dependence on non-renewable oil, which reduces carbon dioxide emissions and air pollution. In 1997 Toyota introduced the world's first hybrid-powered car - the Toyota Prius, which uses oil and electricity as hybrid powers. It is a breakthrough in the innovation of automotive energy, becoming a leader in environmental protection and new energy development. It also takes full consideration of new man-machine model and technology model in design, becoming a pioneer to lead the future development of car. Later, the Prius 04 introduced in 2004 by Toyota is the first high pressure/high volume Toyota with synergy drive system. The advantages of the hybrid system are salient. More importantly, in some cases the car is totally electricity powered. The emissions of car with this synergy drive system are 90 percent lower than that with conventional internal combustion engine. Still, it is impressive that the Prius has broken the axiom that environmental protection and performance cannot reach at the same time.

The application of new energy in new product should pay more attention to the use and development of sustainable energy and renewable energye. After the successful invention of wind driven generator in Denmark in the late $19^{\text {th }}$ century, people gradually realize that natural wind energy is inexhaustible, clean and efficient, and it can be used not only in electricity but also in other various new products.German engineers Dirk.Gion and Stefan-Simmerer designed a new energy car "Wind Surveyor" completely driven by wind in 2011(is shown in fig.1). Its body is made of carbon fiber material and frame of aluminum, so it weighs only about 220 kilograms. It can accommodate two passengers. Though without large amounts of electrical appliances and intelligent operating systems as current available vehicles, it realizes zero emission in the test travel of 4828 kilometers in Australia. The result of this experiment expands the choice of applicable energies that can be used in new energy car.

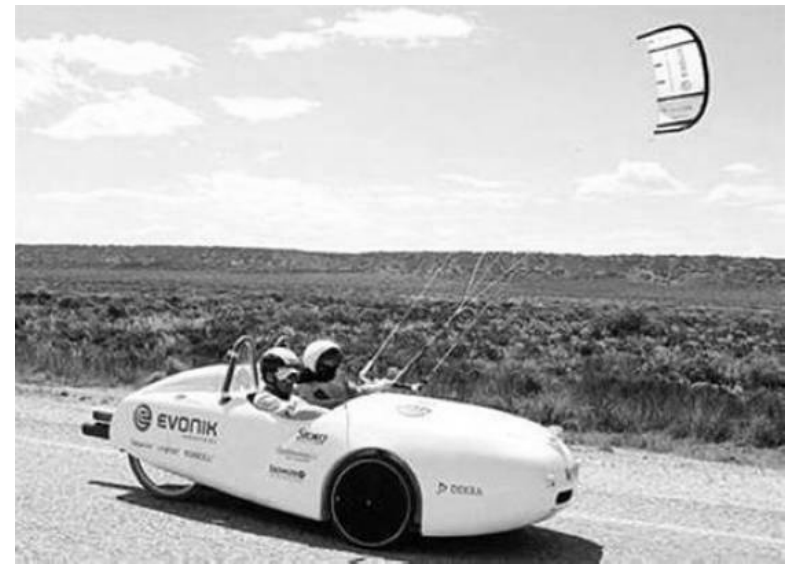

Fig.1. German engineers Dirk·Gion and

Stefan:Simmerer designed The new energy car

"Wind Surveyor".

Except for wind energy, solar energy is also commonly used renewable energy, generally in electricity and water heater for providing heat. Now it is also used in the design of solar energy plane. Switzerland has made out the first diurnal solar energy plane, known as "Sun Drive" (is shown in fig.2). Its wings are covered with 11628 solar cells, which can charge 400 kilograms storage batteries. It uses many carbon fiber composites with weight only about 1600 kilograms. In May 2013 the "Sun Drive" made a record of the longest travel, reaching 1541 kilometers.

The energy used in new product can be obsolete energy, which is recyclable through processes using technology.In June 2012, a Boeing777 driven by biofuels of KLM-Royal Dutch 
Airlines fulfilled a flight from Holland to Brazil(is shown in fig.3). The biofuels that used by this plane is mainly extracted from deserted oil of kitchen. This improved plane depends on kitchen oil extracted by more advanced skill as fuels in place of conventional aerial petroleum and kerosene. By adopting this method, Holland aerial transportation industry plans to reduce its carbon dioxide emissions to its half until 2050. Such way of transforming wastes into resources can reduce dissipation of available resources, and abate pollution and damage to environment.

Coincidentally, England Thames Water Company has cooperated with a local green energy company named $2 \mathrm{OC}$ and has built the world's biggest swill-cooked dirty oil power plant in east London. Its fuels come mainly from animal fats, vegetable oils, fats and so on in London sewers. The electricity generated will be used in dealing with sewage, desalination of seawater and the rest of it goes to the national grid. At that time, it will be able to generate $130 \mathrm{GWh}$ (gigawatt hours) of renewable electricity per year and meet the needs of 39000 ordinary households for one year.
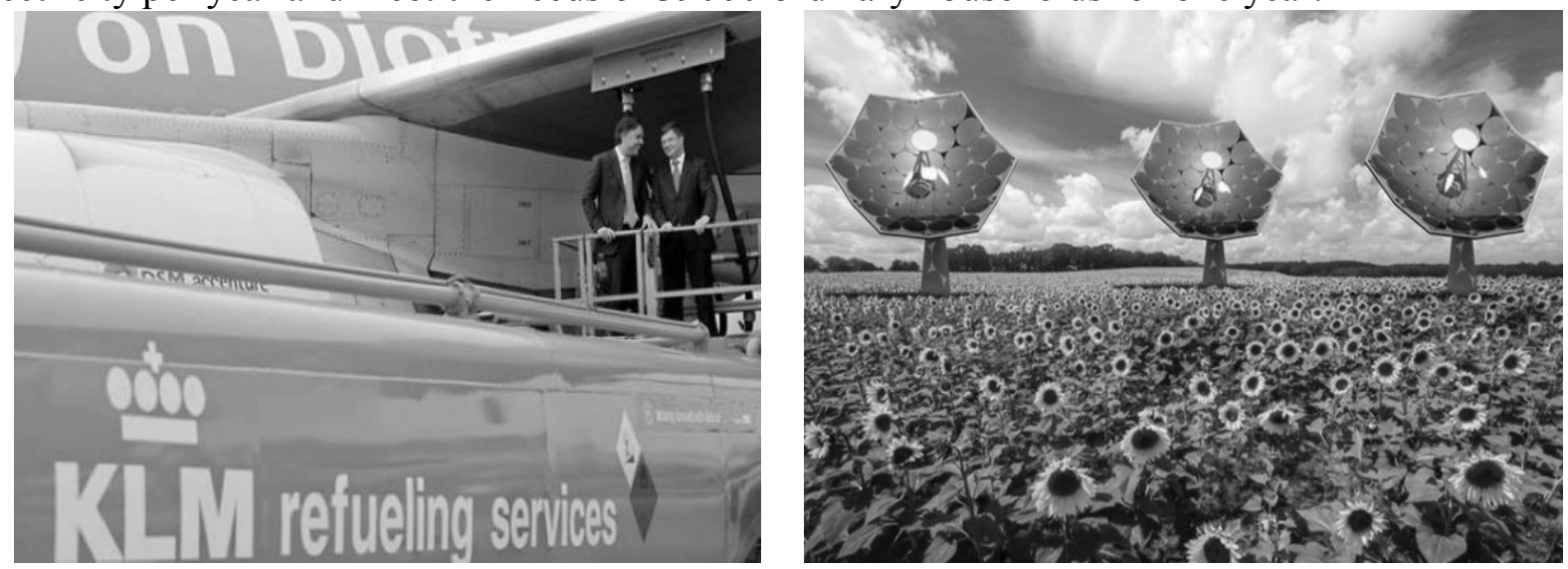

Fig.3. The Boeing777 driven by biofuels ofKLM-Royal Fig.4. IBM "flower" solar photovoltaic system. Dutch Airlines.

Use the existing natural energy to realize the transformation between natural energies. The American IBM has cooperated with Air Light Energy Company and developed a kind of sunflower-shaped solar concentrator, which produces electricity by sunlight(is shown in fig.4). It has a High Concentration Photovoltaic Thermal (HCPVT), like a huge disk and covered with 36 recyclable silver plating plastic mirrors. The mirrors will gather sunlight on photovoltaic chips, which can collect $80 \%$ of sunlight and transform it into usable energy. Its auxiliary tracking system can change its direction according to the angle of sunlight. The hundreds of "rectification chips" installed on the receptor can generate 25 kilowatts electric energy and generate electricity by exploiting waste heat properly and fully. It can also produce desalted drinking water with per square meter of processing system producing 30-40 liters drinking water, equal to a person's needs one day. In developing this new product, the two companies also pay attention to security. A big-sized transparent hull is installed around the whole concentrator in case that birds may be burnt to death when fly over the hot area.

The Korean Yongin University has developed a kind of hula hoop washing machine, by which you can wash clothes while keeping fit. This washing machine works by the power from circling hula hoop. It is a revolutionary new product by transforming kinetic energy to electric energy(is shown in fig.5).

The application of new energy to new product will raise its value comparing to the old one.Designer Alain Gilles has designed the Nomad lamps and lanterns with various purposes. Comparing to the former solar lamps and lanterns, its special point lies in the discretion of solar panel and lamps and lanterns, which lightens itself and is convenient to carry. Its structure also renders itself more functions, able to put on table, able to hang and convenient to carry for outside activity. What's more, it is easy to operate, with one button you can switch for different degrees of brightness. After one day's use, it can still give out light for 12 to 35 hours. The discrete structure of solar panel and lamps and lanterns provides convenience for long distance transportation. Still, by using solar energy, the expenses cut down. In other words, it reduces expenses of transportation and use, and promotes its function as well as its value(is shown in fig.6).

when applying new energy in new product, the original using method should be retained properly according to the type of the product. It will save time for users to learn how to use and 
at the same time meet users' emotional attach to the product.England Seymourpowell Design Company has produced a type of hydrogen driven motorcycle ENV, which adopts nuclear fuel cells and is powered by hydrogen(is shown in fig.7). This motorcycle can run for 50 miles per hour at its maximum and can drive for 4 hours with fuel tank full. The new energy and new technology successfully realize zero pollution, but the only problem is that there is nearly no sound from engine when drive, which weakens engine fans' feeling of pleasure because they can not hear the growl as common motorcycles jar when drive in high speed, and brings hidden danger because pedestrians cannot feel whether the motorcycle is near or far by the sound. Therefore, this new product have to mimic the noise of common motorcycle's engine to compensate engine fans' lost feelings when drive them and to safeguard pedestrians.
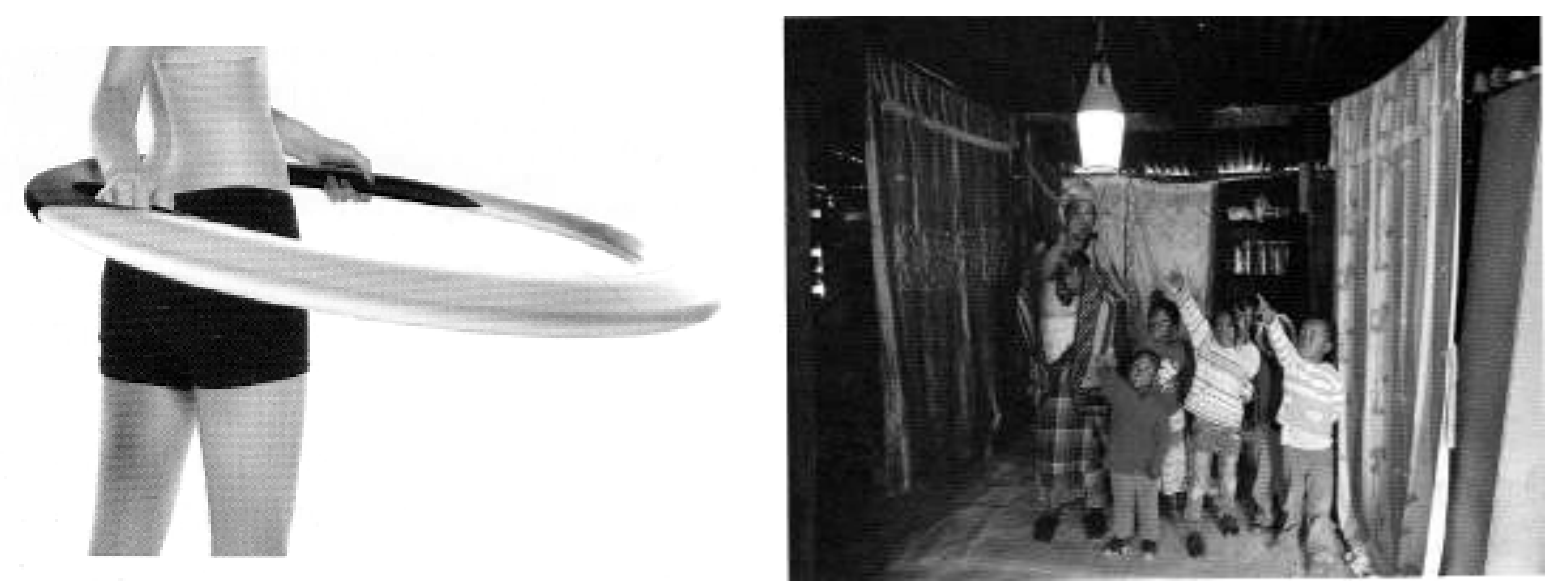

Fig.5. The Hula hoop washing machine.

Fig.6.The Nomad lamps and lanterns with various purposes .

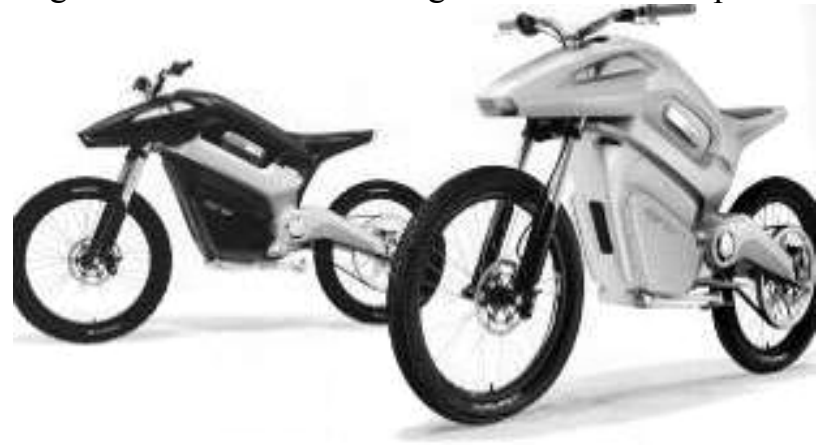

Fig.7.The Hydrogen powered motorcycle ENV.

\section{Conclusion}

In general, the application of new energy in new product reduces the energy consumption and improves the value of product in one way, which makes it more competitive than its counterpart in the market and also is beneficial to build a low-carbon society.

\section{References}

[1] Liang Benfan, Li Hexin. Transforming to Low Carbon: the New Theme of Chinese Modernization [A]. The Chance and Challenge of Modernization --- The Eighth Symposium of Chinese Modernization Research Forum[C].2010.

[2] Robert·J'Thomas. The Successful Stories of New Products. Beijing: China Renmin University Press, 2002. 